\title{
Some factors affecting the uniaxial strength of weak sandstones
}

\author{
Hongey Chen · Zer-Ye Hu
}

\begin{abstract}
The paper reports on a study of the weak sandstones of the Shihti and Kweichulin Formations to the east of Taipei, Taiwan. The results indicate that the wave velocity and uniaxial compressive strength (UCS) of the samples decreased as water content increased, while wave velocity, UCS and slake durability increased with increasing porosity. Regression analyses demonstrated that wave velocity, UCS and slake durability decreased with increased quartz content. The values of these engineering properties also increased with a higher proportion of matrix/detritus, although the exact nature of the interrelationships between these factors is not clear.
\end{abstract}

Résumé L'article présente une étude de grès tendres des formations de Shihti et Kweichulin à l'est de Taipeh (Taiwan). Les résultats indiquent que la vitesse du son et la résistance à la compression simple des échantillons diminuent quand la teneur en eau augmente et que la résistance à la compression simple et l'indice d'altérabilité augmentent quand la porosité augmente. Les analyses de régression ont montré que la vitesse du son, la résistance à la compression simple et l'indice d'altérabilité diminuent lorsque la teneur en quartz augmente. Par ailleurs, les valeurs de ces paramètres augmentent lorsque le rapport matrice/éléments détritiques augmente, bien que l'explication de cette relation ne soit pas claire.

Keywords Compressive strength $\cdot$ Weak sandstone $\cdot$ Matrix $\cdot$ Detritus $\cdot$ Taiwan

Received: 27 November 2000 / Accepted: 16 March 2003

Published online: 2 October 2003

(C) Springer-Verlag 2003
Mots clés Résistance à la compression simple · Grès tendres - Matrice - Eléments détritiques - Taiwan

\section{Introduction}

A typical property measured when analyzing the engineering behaviour of weak rock is its uniaxial compressive strength (UCS); in the case of weak sandstones, this is usually between 0.5 and $25 \mathrm{MPa}$ (Geological Society London 1970; Brown 1981). Factors affecting the properties of weak rock include poor cementation, weathering, tectonic disturbance and large pore spaces (Olivera 1993). In addition, the mineral composition of the rock is also important, as well as porosity, water content, density and particle size-properties that are known to influence the wave velocity, compressive strength and slake durability of weak sandstone (Bell and Culshaw 1993).

Although some researchers have found that UCS has a strong positive correlation with quartz content (Gunsallus and Kulhaway 1984; Shakoor and Bonelli 1991), others, such as Bell (1978) and Ulusay et al. (1994), considered the quartz content to be unrelated to UCS values. However, if sandstone is well cemented with matrix minerals of quartz or calcite, they will impart a greater strength to the rock mass than when a clay matrix is present (Vutukuri et al. 1974; Barton et al. 1993). Work by Bell and Culshaw (1993) and Yuan (1996) indicates that the UCS of weak sandstones decreases when the particle size, porosity and the water content increase, while Onodera and Asoka (1980) also report a decrease in rock strength with an increase in particle size.

This paper presents the results of various experimental tests on weak sandstones from the Kweichulin Formation and the Shihti Formation in the eastern part of the Taipei Basin and attempts to quantify the relative importance of the different factors affecting their compressive strength using multiple regression analyses.

\section{Geological conditions}

The study area is located near the intersection of the hilly and lowland areas of the eastern part of Taipei City. It is 
well vegetated and surrounded by hills on the southern, eastern and western sides. The trend of the hills is northwest/south-east while the beds dip towards the south.

The study area includes the region of the Taipei fault (Huang 1988), which separates the Shihti Formation and the south side of the Kweichulin Formation of Miocene age on the north (Fig. 1). The trend of the Kweichulin Formation ranges between $N 45^{\circ} \mathrm{E}$ and $\mathrm{N} 50^{\circ} \mathrm{E}$, with a southerly dip of $30^{\circ}$. The orientation of the Shihti Formation varies between $\mathrm{N} 65^{\circ} \mathrm{W}$ and $\mathrm{N} 75^{\circ} \mathrm{E}$ and the dip is southward at $80^{\circ}$. Where seen in outcrop, the bedrock appears in a fractured condition.

The Shihti Formation is the most important formation for coal in the northwestern part of Taiwan. It is of Miocene age -18 to 20 million years old. The most common feature of the formation is the presence of laminated, interbedded, grey-black shale and light grey sandstone. The thickness of the laminations varies from a few millimetres to a few centimetres, indicating a tidal shore, delta or a swamp-like accumulation. The shale in the Shihti Formation is dark grey to grey-black and rich in carbon. The sandstone is rich in feldspar and is usually light grey to white.

In the north part of Taiwan, the Kweichulin Formation is of Mid-Miocene age and is characterized by an abundance

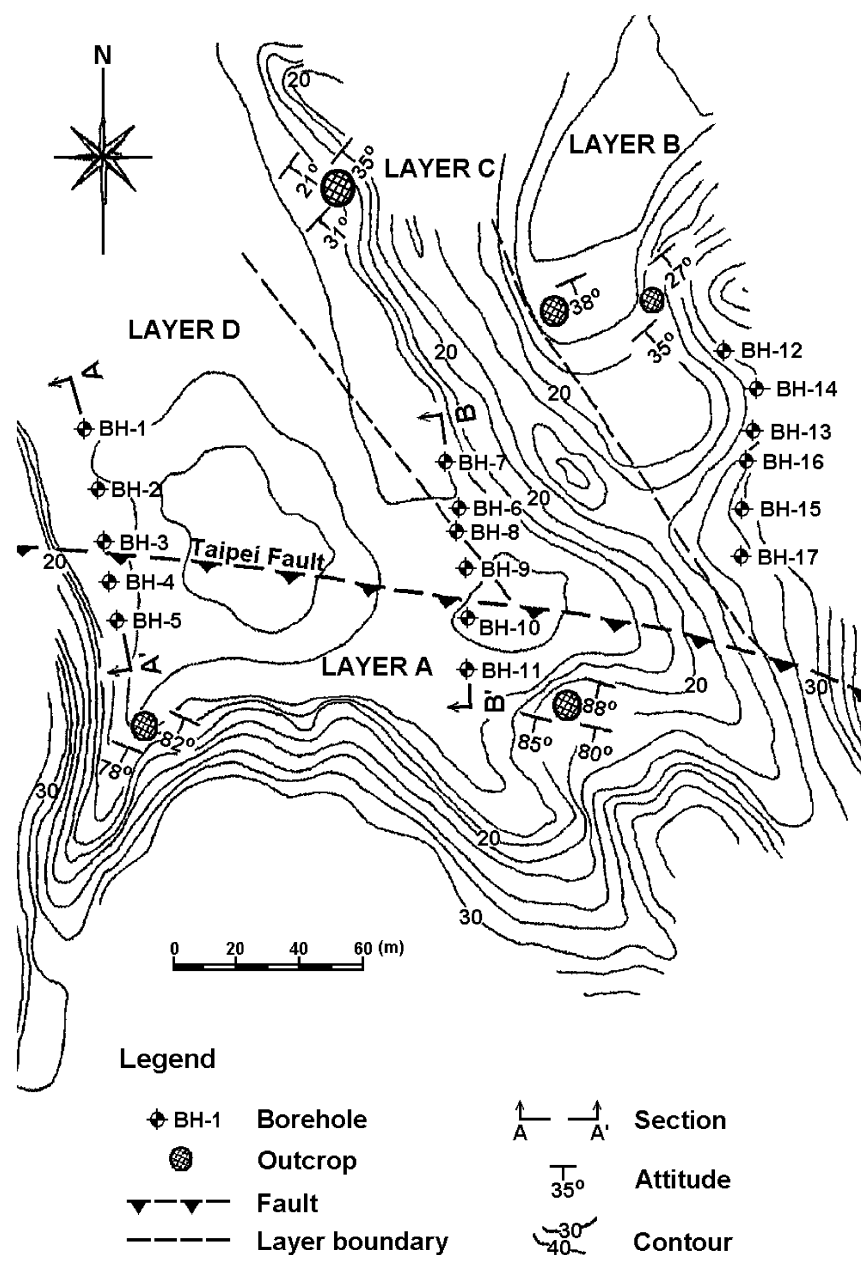

Fig. 1

Geological map of the study area showing borehole locations of clayey massive sandstones (Ho 1986). The sandstone is light green in colour and interbedded with dark grey shale.

\section{Stratigraphy}

The study took rock core samples of $54 \mathrm{~mm}$ diameter from 17 boreholes. Boreholes 4, 5, 10 and 11 clearly showed the common characteristics of the Shihti Formation with laminations and coal layers. Boreholes 1 to 3, 6 to 9 and 12 to 17 mainly penetrated the grey silty massive sandstone of the Kweichulin Formation, which is characterized by a loose cementation and contains interbeds of sandstone and shale. The thickness of rock formations is shown in section A-A' (Fig. 2). The lithological characteristics of the rock layers are given in Table 1 .

Four lithostratigraphic layers were distinguished in the Shihti and Kweichulin Formations in the study area. Layer A, on the south side of the Taipei Fault, is part of the Shihti Formation and more than $30 \mathrm{~m}$ thick. The rock types are white to grey, clayey massive sandstone and coal interbedded with dark grey shale. Layers B, C and D are on the north side of the Taipei Fault and belong to the Kweichulin Formation. Layers B and D are some $40 \mathrm{~m}$ thick and are composed of fine- to medium-grained, light greenish-grey to dark grey, clayey massive sandstones interbedded with grey shale. Layer $C$ is between 15 and $25 \mathrm{~m}$ thick and consists of fine- to medium-grained, grey, clayey massive sandstone.

All the rock cores appeared to have poor cementation and were in a fractured state.

\section{Experimental methods}

Cylinders of $54 \mathrm{~mm}$ diameter were taken from the different layers and tests undertaken to determine the physical properties, wave velocity, uniaxial compressive strength and slake durability of the materials. To establish the physical properties, water content, porosity and density were determined following the International Society of Rock Mechanics methods (Brown 1981). The longitudinal and shear wave velocity were calculated from the travel time through the core sample from the generator to a receiver at the opposite end, following the procedures described in ASTM (1980).

UCS was determined following ISRM methods (Brown 1981). Slake durability testing included two cycles for each sample and again followed ISRM methods (Brown 1981).

\section{Results}

\section{Mineral composition}

Mineral composition was determined from an examination of 59 thin sections. The sandstones studied were found to consist of quartz, detritus and matrix materials. The 




A-A' section
Fig. 2

Columnar sections showing the Kweichulin and Shihti Formations, based on borehole data, in relation to the Taipei Fault

Table 1

Stratigraphic description of the study area

\begin{tabular}{|c|c|c|}
\hline Formation & Layer & Description \\
\hline Kweichulin Formation & $\mathrm{C}$ & $\begin{array}{l}\text { The thickness of this layer ranges from } 15 \text { to } 25 \mathrm{~m} \text {. It is distributed on the northern side of the Taipei Fault, } \\
\text { below layer B. The rock type is a fine- to medium-grained massive sandstone interbedded with dark grey } \\
\text { shale }\end{array}$ \\
\hline
\end{tabular}

Table 2

Mineral composition (in \%) of the various layers of weak sandstone in the study area

\begin{tabular}{|c|c|c|c|c|c|c|}
\hline Formation/layer & Quartz & Feldspar & Calcite & Detritus & Matrix & Others \\
\hline Shihti/layer A & $21.1-62.7$ & $1.5-10.3$ & $0-2.7$ & $3.7-17.3$ & $19.8-71.9$ & $0-4.7$ \\
\hline Kweichulin/layer B & $34.3-69.7$ & $1.3-7.3$ & $0-2.3$ & $4.3-19.2$ & $13.7-51.3$ & $0-4.3$ \\
\hline Kweichulin/layer C & $37.7-56.5$ & $0.3-3.0$ & $0-25.2$ & $13.7-26.7$ & $1.7-34.3$ & $0-1$ \\
\hline Kweichulin/layer D & $25.0-72.3$ & $2.0-10.7$ & $0-12.7$ & $7.0-19.3$ & $4.7-64.3$ & $0-2.3$ \\
\hline
\end{tabular}

feldspar content was less than $10.7 \%$, while there were only minor amounts of calcite and other minerals.

In the Shihti Formation the quartz content varies from 21.1 to $62.7 \%$, the detritus from 3.7 to $17.3 \%$ and the matrix material from 19.8 to $71.9 \%$ (Table 2). The mineral composition of the Kweichulin Formation also varied widely: quartz from 25 to $72.3 \%$, detritus from 4.3 to $26.7 \%$ and the matrix material from 4.7 to $64.3 \%$.

The average amount of detritus was higher in the Kweichilun Formation compared with the Shihti Formation, while the feldspar content was higher in the Shihti Formation. In general, approximately $30 \%$ of the samples of weak sandstone in the study area consisted of a matrix of primarily clay material.

The results of the X-ray diffraction demonstrated that the Shihti Formation has more than 50\% kaolinite (46 to $84 \%$ ) but a chlorite content generally less than $1 \%$. In the Kweichulin Formation, the kaolinite content does not rise above $30.3 \%$, but, as seen in Table 3, the chlorites can reach as high as $53 \%$ (layer $\mathrm{D}$ ). The maximum illite found 
Table 3

Results of semi-quantitative analysis of clay minerals in various layers (in \%)

\begin{tabular}{|c|c|c|c|c|}
\hline Formation/layer & Smectite & Illite & Chlorite & Kaolinite \\
\hline Shihti/layer A & 0 & $15.8-53.8$ & $0-1.1$ & $46.2-84.2$ \\
\hline Kweichulin/layer B & $8.1-22.3$ & $42.4-54.1$ & $11.1-26.3$ & $18.5-30.3$ \\
\hline Kweichulin/layer C & $5.1-17.4$ & $40.3-52.1$ & $20.6-20.7$ & $21.7-22.1$ \\
\hline Kweichulin/layer D & $0-20.1$ & $18.4-54.5$ & $19.6-53.3$ & $0-26.4$ \\
\hline
\end{tabular}

Table 4

Physical properties of various layers in the study area (in \%)

\begin{tabular}{|c|c|c|c|c|}
\hline Formation/layer & Water content & Porosity & Density & Specific gravity \\
\hline Shihti/layer A & $0.61-3.43$ & $4-19.5$ & $2.14-2.39$ & $2.54-2.68$ \\
\hline Kweichulin/layer B & $0.43-2.37$ & $7.5-26.5$ & $1.95-2.45$ & $2.55-2.65$ \\
\hline Kweichulin/layer C & $0.17-1.05$ & $3.2-13.4$ & $2.33-2.60$ & $2.61-2.68$ \\
\hline Kweichulin/layer D & $0.45-3.5$ & $8.0-25.1$ & $2.00-2.43$ & $2.58-2.66$ \\
\hline
\end{tabular}

was $54.5 \%$ in layer $\mathrm{D}$, although each of the layers has a maximum illite of over $50 \%$. No smectite was found in the Shihti Formation or in some samples from layer $\mathrm{D}$ of the Kweichulin. In layers $\mathrm{B}, \mathrm{C}$ and $\mathrm{D}$ the maximum smectite present varied between 17 and 22\% (Table 3).

\section{Physical properties}

The results of the water content, porosity and density tests are shown in Table 4 . It can be seen that the average water content of the weak sandstone in the study area is less than $3.5 \%$. In general, layer A (Shihti Formation) has the highest water content while layer $\mathrm{C}$ (Kweichulin Formation) has the lowest. The average porosity of the weak sandstone in the study area ranged from 3.2 (lowest value in layer C) to $26.5 \%$ (highest value in layer B). In general there was little difference in the porosity of the individual lithological layers.

The density ranged from 1.95 (lowest value in layer B) to $2.60 \mathrm{~g} / \mathrm{cm}^{3}$ (highest value in layer $\mathrm{C}$ ). It will be noted from Table 4 that in the Shihti Formation the difference in density is within $0.25 \mathrm{~g} / \mathrm{cm}^{3}$. Whilst a similar difference was recorded in layer $\mathrm{C}$ of the Kweichulin Formation $\left(0.27 \mathrm{~g} / \mathrm{cm}^{3}\right)$, it rose to $0.43 \mathrm{~g} / \mathrm{cm}^{3}$ in layer D and $0.5 \mathrm{~g} / \mathrm{cm}^{3}$ in layer B. Although not obvious from Table 4, the higher densities correlate with the lower porosity values and the thin section observations.

The specific gravity of the weak sandstone ranged from 2.54 to 2.68 , with no evidence of an influence of the kaolinite and coal known to be present in the Shihiti Formation.

\section{Wave velocities}

The results of the longitudinal and shear wave velocity measurements are shown in Table 5. The longitudinal wave velocity ranged from 0.48 to $4.84 \mathrm{~km} / \mathrm{s}$, while the shear wave velocity varied between 0.32 and $2.98 \mathrm{~km} / \mathrm{s}$. As seen in the table, the measurements were generally higher
Table 5

Results of longitudinal and shear wave measurements for various layers in the study area (in $\mathrm{km} / \mathrm{s}$ )

\begin{tabular}{|c|c|c|}
\hline Formation/layer & Longitudinal wave & Shear wave \\
\hline Shihti/layer A & $0.92-2.01$ & $0.50-1.14$ \\
\hline Kweichulin/layer B & $0.48-2.75$ & $0.32-1.66$ \\
\hline Kweichulin/layer C & $2.00-4.84$ & $1.29-2.98$ \\
\hline Kweichulin/layer D & $0.50-1.98$ & $0.34-1.31$ \\
\hline
\end{tabular}

for the material from the Kweichulin Formation than from the Shihti Formation, although the results from layer A were similar to those from layer $\mathrm{D}$, with layer $\mathrm{C}$ having the highest measurements. These results are lower than some others reported in the literature. Bieniawski (1984) found that the longitudinal wave velocity of sandstone ranged from 1.1 to $4.5 \mathrm{~km} / \mathrm{s}$, while Yuan (1996) reported results from experiments on material from the Kweichulin Formation indicating longitudinal wave velocities of 1.64 to $2.51 \mathrm{~km} / \mathrm{s}$ and shear wave velocities of 1.3 to $2 \mathrm{~km} / \mathrm{s}$.

\section{Uniaxial compressive strength}

The UCS of the 59 weak sandstone samples was determined and longitudinal and lateral strain measurements obtained using the linear variable differential transformer (LVDT). A few strain gauges were destroyed during the testing procedure; for these samples the total volume changes were derived from the LVDT data and converted to a strain measurement.

Table 6 shows that the UCS of the tested samples from the Shihti Formation (layer A) varied between 0.25 and $5.14 \mathrm{MPa}$, the average value being 2.15 $\mathrm{MPa}$. Samples from this layer also gave the lowest axial strain, although the lateral strain obtained from strain gauge measurements was similar to those of layers B, C and D from the Kweichulin Formation. Layer $\mathrm{C}$ had a relatively consistent strength of 14.35 to $18.98 \mathrm{MPa}$, compared with layers $\mathrm{B}$ and $\mathrm{D}$ where some low strengths were recorded (as low as $0.31 \mathrm{MPa}$ in layer D). 
Table 6

Results of uniaxial compressive strength (UCS) tests and stress-strain measurements for the various layers in the study area

\begin{tabular}{|c|c|c|c|c|}
\hline Formation/layer & $\begin{array}{l}\mathrm{UCS} \\
(\mathrm{MPa})\end{array}$ & $\begin{array}{l}\text { Axial strain }{ }^{\mathrm{a}} \\
(\%)\end{array}$ & $\begin{array}{l}\text { Axial strain } \\
(\%)\end{array}$ & $\begin{array}{l}\text { Lateral strain }{ }^{\mathrm{b}} \\
(\%)\end{array}$ \\
\hline Shihti/layer A & $0.25-5.14$ & $0.37-2.1$ & $0.13-0.77$ & $0.07-0.52$ \\
\hline Kweichulin/layer B & $0.77-19.21$ & $0.87-1.76$ & $0.1-0.82$ & $0.04-0.49$ \\
\hline Kweichulin/layer C & $14.35-18.98$ & $1.13-1.43$ & $0.25-0.67$ & $0.09-0.47$ \\
\hline Kweichulin/layer D & $0.31-10.17$ & $0.42-2.27$ & $0.09-1.48$ & $0.03-0.56$ \\
\hline
\end{tabular}

${ }^{\mathrm{a}}$ LVDT measurements

${ }^{\mathrm{b}}$ Strain gauge measurements

Table 7

Percentage of various grades of UCS for the layers in the study area

\begin{tabular}{|c|c|c|c|}
\hline Formation/layer & R0 & $\mathrm{R} 1$ & $\mathrm{R} 2$ \\
\hline & Extremely weak rock & Very weak rock & Weak rock \\
\hline Shihti/layer A & $\begin{array}{l}3 \text { sets } \\
(23.1 \%)\end{array}$ & $\begin{array}{l}9 \text { sets } \\
(69.2 \%)\end{array}$ & $\begin{array}{l}1 \text { set } \\
(7.7 \%)\end{array}$ \\
\hline Kweichulin/layer B & $\begin{array}{l}1 \text { set } \\
(5.6 \%)\end{array}$ & $\begin{array}{l}6 \text { sets } \\
(33.3 \%)\end{array}$ & $\begin{array}{l}11 \text { sets } \\
(61.1 \%)\end{array}$ \\
\hline Kweichulin/layer C & - & - & $\begin{array}{l}3 \text { sets } \\
(75 \%)\end{array}$ \\
\hline Kweichulin/layer D & $\begin{array}{l}7 \text { sets } \\
(29.2 \%)\end{array}$ & $\begin{array}{l}9 \text { sets } \\
(37.5 \%)\end{array}$ & $\begin{array}{l}8 \text { sets } \\
(33.3 \%)\end{array}$ \\
\hline
\end{tabular}

Table 8

Results of slake durability tests for various layers in the study area (in $\mathrm{km} / \mathrm{s}$ )

\begin{tabular}{|c|c|c|c|}
\hline Formation/layer & First cycle index & Second cycle index & Grade \\
\hline Shihti/layer A & $10.6-84.3$ & $0.5-59.0$ & Very low \\
\hline Kweichulin/layer B & $13.8-87.4$ & $1.9-75.2$ & Low-medium \\
\hline Kweichulin/layer C & $8.1-78.3$ & $1.3-65.5$ & Low-medium \\
\hline Kweichulin/layer D & $2.4-88.5$ & $0.2-73.4$ & Very low \\
\hline
\end{tabular}

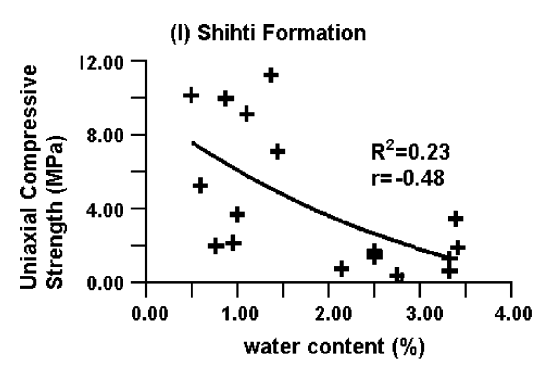

(II) Kweichulin Formation

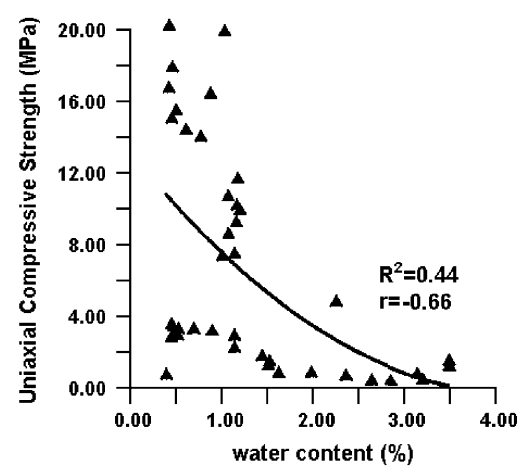

(a) Water content

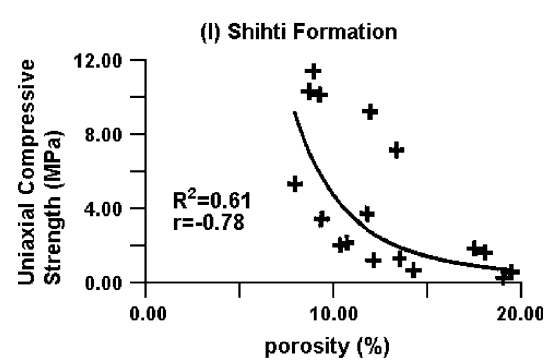

(II) Kweichulin Formation

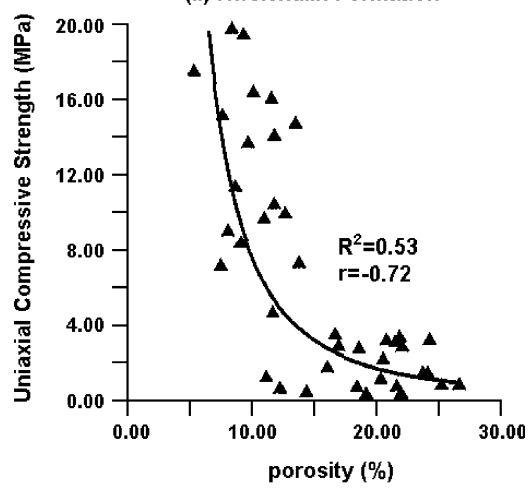

(b) Porosity
Fig. 3

Regression correction coefficient and the various linear relationships between uniaxial compressive strength and physical properties (a water content and $\mathbf{b}$ porosity) in the Shihti and Kweichulin Formations 
The strain gauge results suggest that there were clear end The UCS for rocks is sometimes classified into seven effects, which probably influenced the results of all the compressive tests. The associated lateral strain was less than $0.6 \%$ in all cases. grades (ISRM 1978) designated by the codes R0 to R6. Approximately $69 \%$ of the samples from the Shihti Formation would be classified as R1 (very weak rock). For the
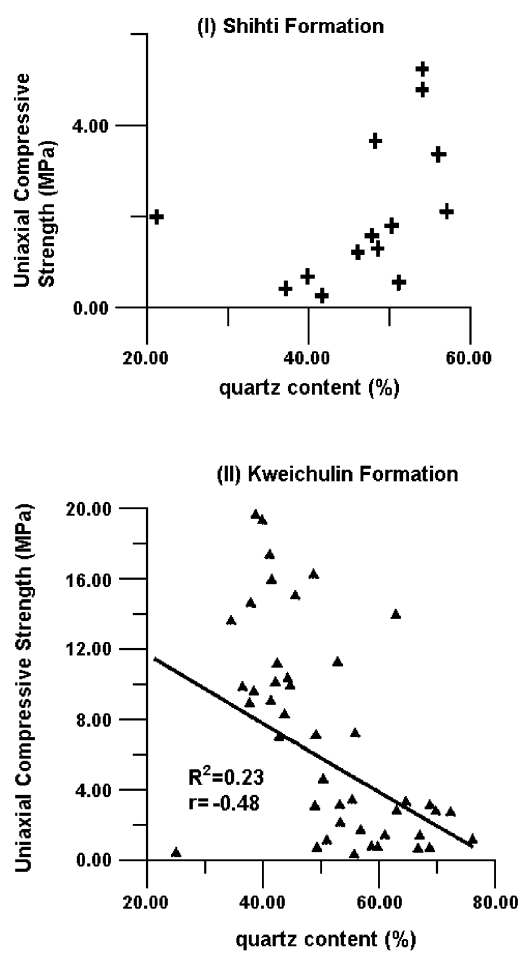

(a) Quartz content
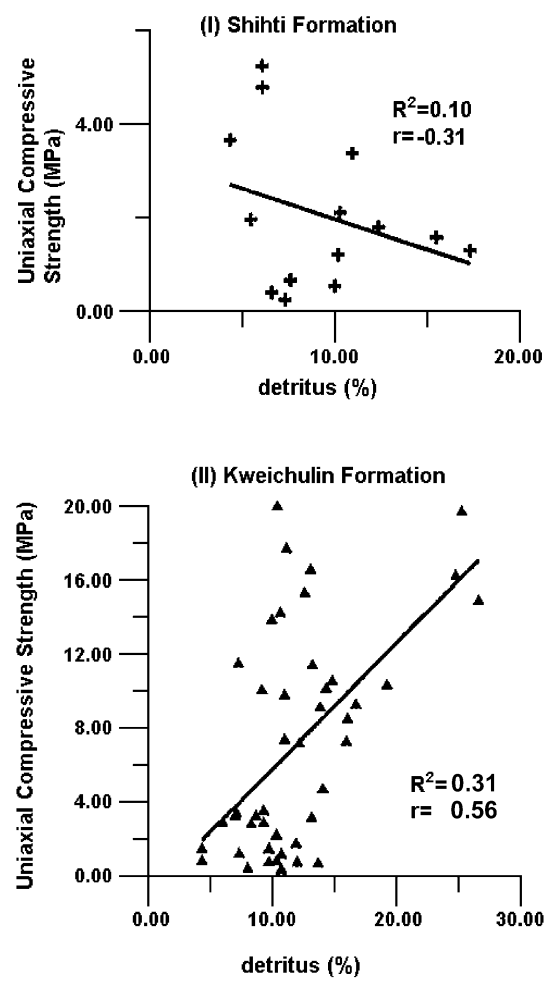

(c) Detritus
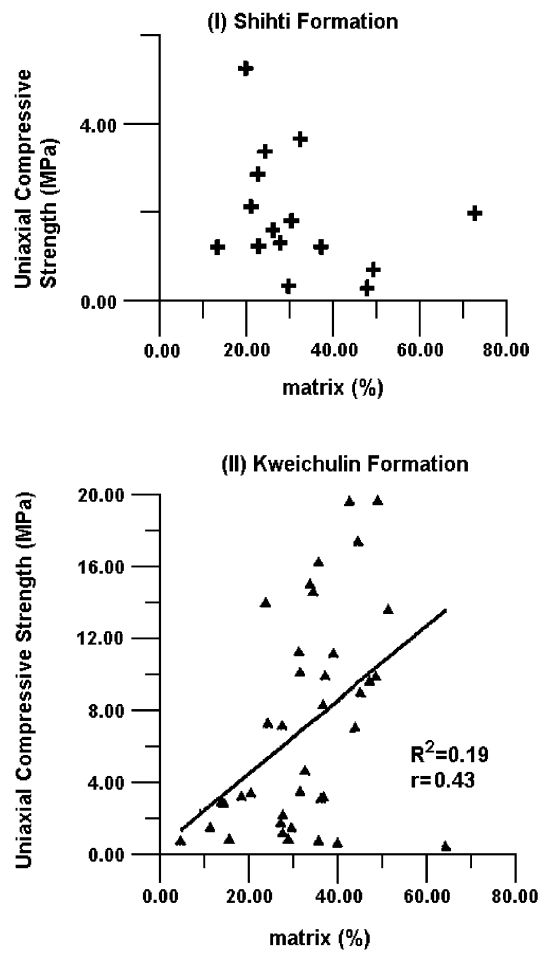

(b) Matrix
Fig. 4

Regression correction coefficient and the various linear relationships between uniaxial compressive strength and minerals composition (a quartz content; b matrix; c detritus) in the Shihti and Kweichulin Formations 
Kweichulin Formation samples, $61 \%$ of layer B and $75 \%$ of layer $\mathrm{C}$ were in category $\mathrm{R} 2$, while all the tested samples were graded between R0 and R2 (Table 7) with the exception of $25 \%$ of layer $\mathrm{C}$ which was graded above category R2.

\section{Slake durability}

Slake durability tests were undertaken on 30 samples in order to determine their resistance to weathering. The results were categorized following Gamble (1971) as shown in Table 8. The slake durability index was found to range from "very low" to "medium", with most of the samples from layers A and D falling into the "very low" category and those from layers $\mathrm{B}$ and $\mathrm{C}$ in the low to medium grade.

\section{Discussion}

Interrelationships between physical properties

The relationships between water content and porosity and UCS are shown in Fig. 3. Figure 3a shows a weak $(r=-0.48$, -0.66) inverse parabolic relationship between UCS and water content. Atkinson (1982) points out that the chemical reaction of water with the $\mathrm{SiO}_{2}$ in the sandstone can form an ionic reaction $[\mathrm{H}-\mathrm{O}-\mathrm{H}]+[-\mathrm{Si}-\mathrm{OH} . \mathrm{HO}-\mathrm{Si}-]$. This stress corrosion phenomenon produces a lower strength in the UCS tests.
When the water content of the weak sandstone samples was less than $1 \%$, the UCS decreased rapidly with increasing water content. However, the decrease in UCS was much less where the initial water content was higher. The results also suggest that the pore-water pressure did not affect the UCS - consistent with the findings of Hawkins and McConnell (1992).

Figure $3 \mathrm{~b}$ shows the increased significance of the inverse parabolic relation between UCS and porosity (significance level: $r=-0.78,-0.72$ ). While the UCS decreases as the porosity increases, when the porosity is less than $15 \%$, the UCS increases rapidly with further decreases in porosity.

\section{Interrelationships with mineral composition}

The results of the tests of UCS, wave velocity and slake durability are compared with mineral composition in Fig. 4. Figure 4a shows an inverse linear relationship between quartz content and UCS, although there is no statistically significant trend for the material in the Shihti Formation and the result for the Kweichulin Formation samples is of marginal significance $(r=-0.48)$. Figure $4 \mathrm{~b}$ shows a positive linear relationship between the proportion of matrix material and UCS, although again this is not statistically significant for the Shihti Formation samples and for the samples from layers B, C and D $(r=0.43)$. Figure $4 \mathrm{c}$ indicates both positive and inverse relations between UCS and proportion of detritus with correlation coefficients $(r)$ of 0.5 . A positive relationship between UCS and matrix/detritus content was found for the Kweichulin Formation samples, but for the Shihti Formation material the positive trend is not clear. This would suggest that the
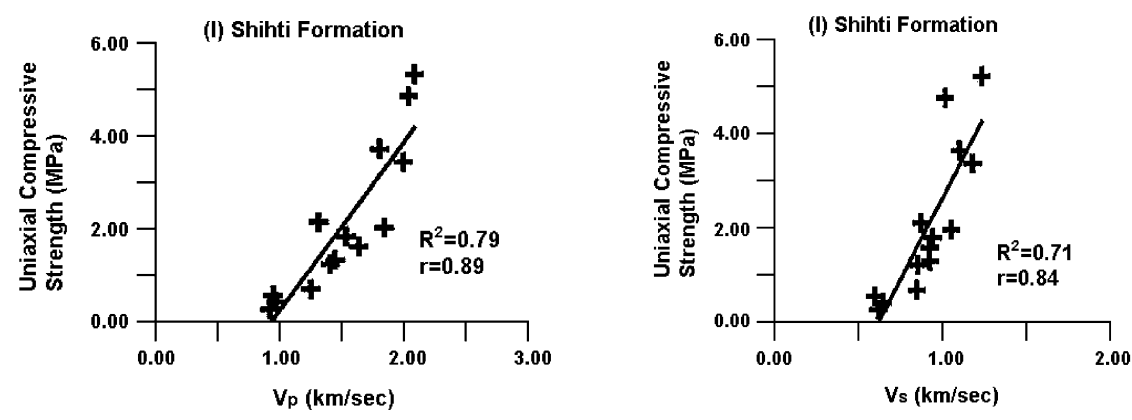

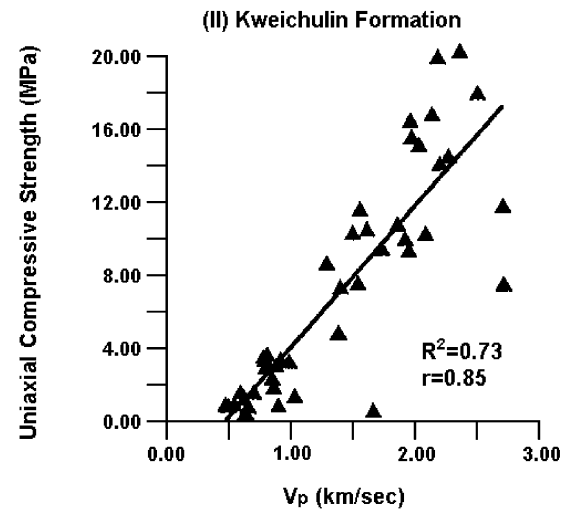

(a) Longitudinal wave

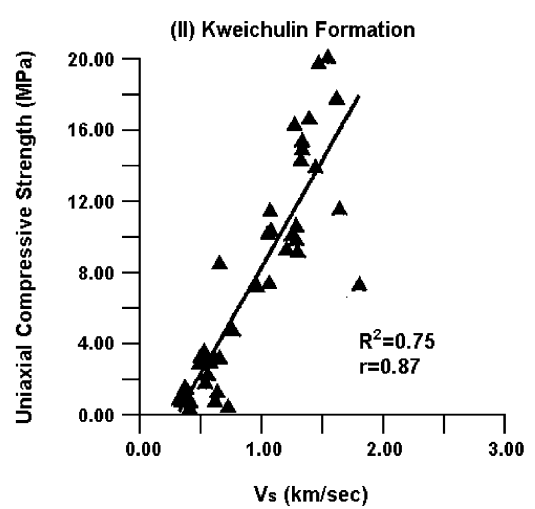

(b) Shear wave
Fig. 5

Regression correction coefficient and the various linear relationships between uniaxial compressive strength and a longitudinal wave $(V p)$ and $\mathbf{b}$ shear wave $(V s)$ in the Shihti and Kweichulin Formations 

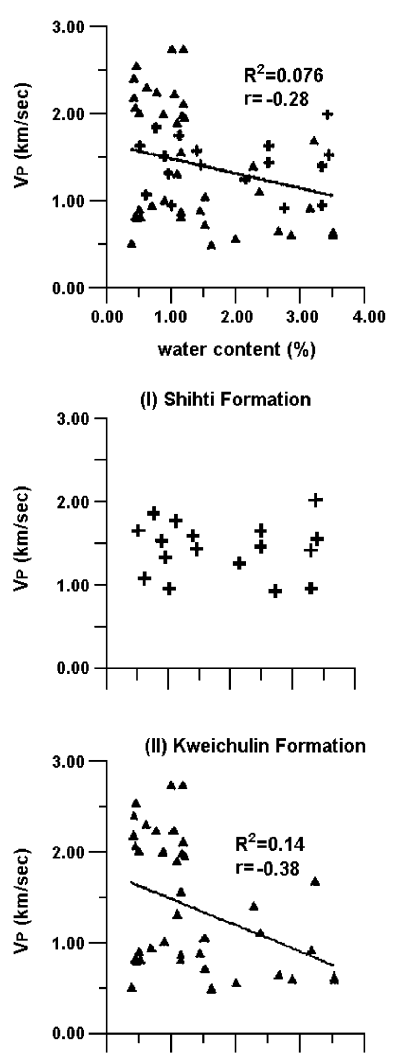

(a) Water content
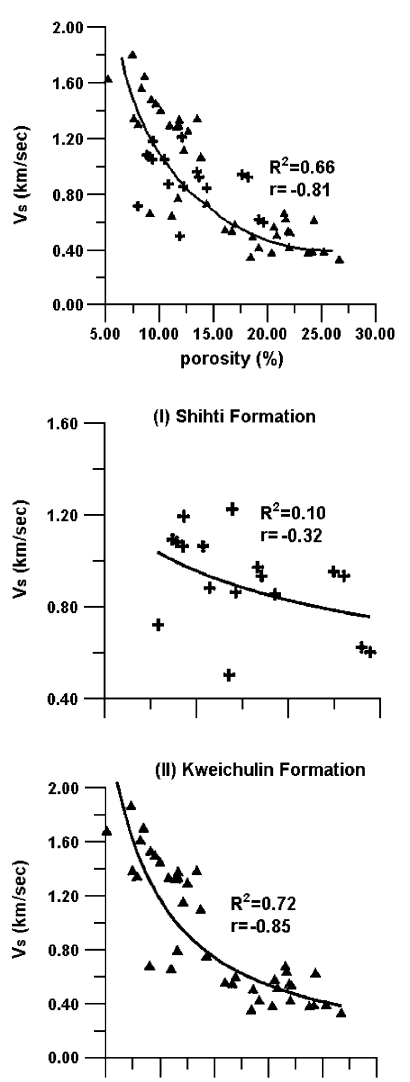

(d) Porosity
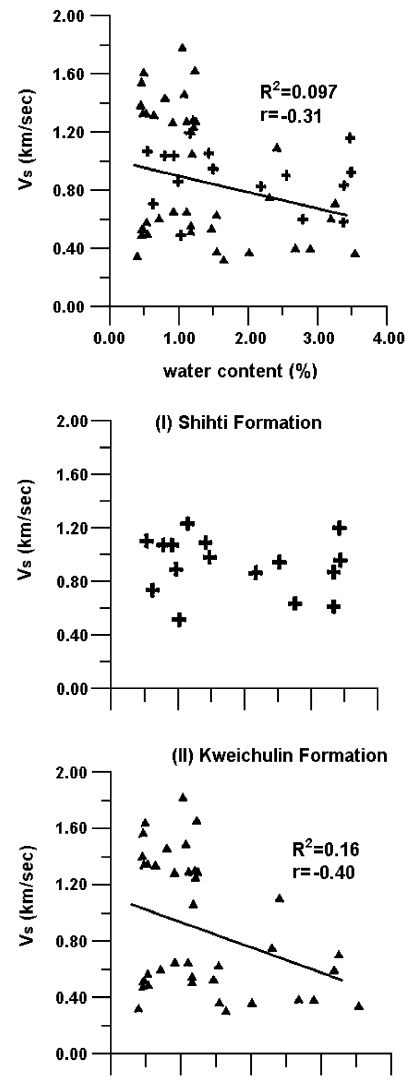

(b) Water content
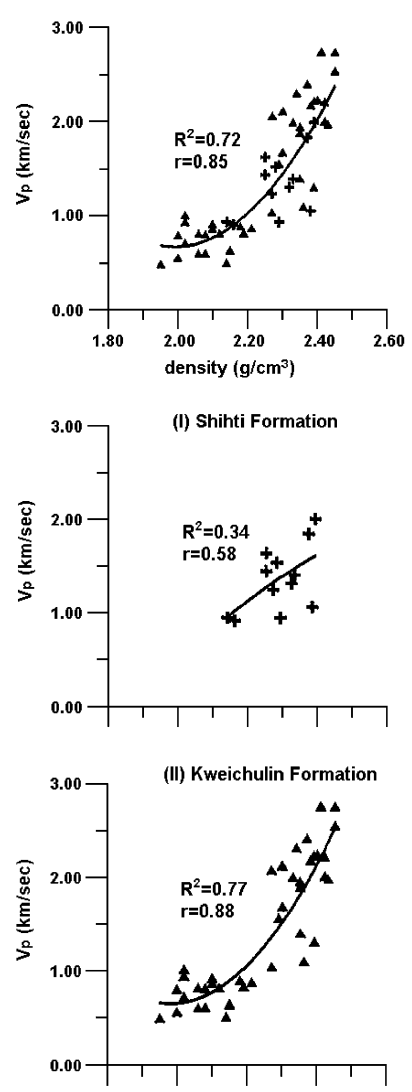

(e) Density
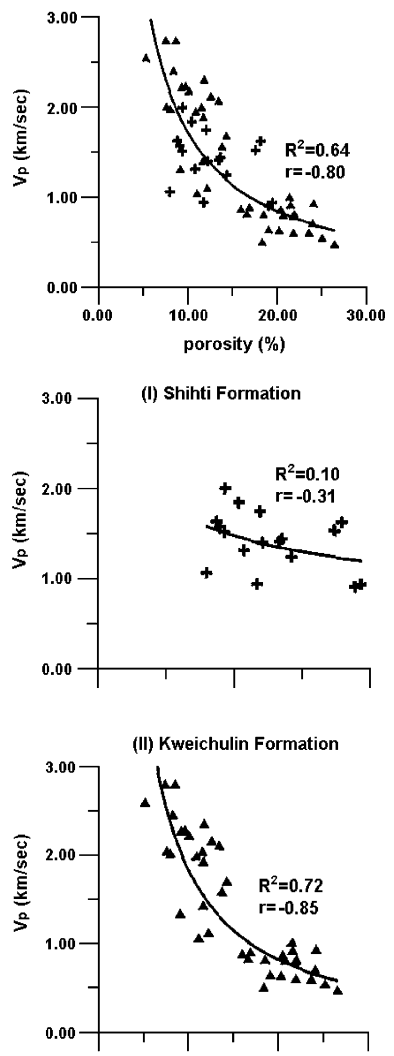

(c) Porosity
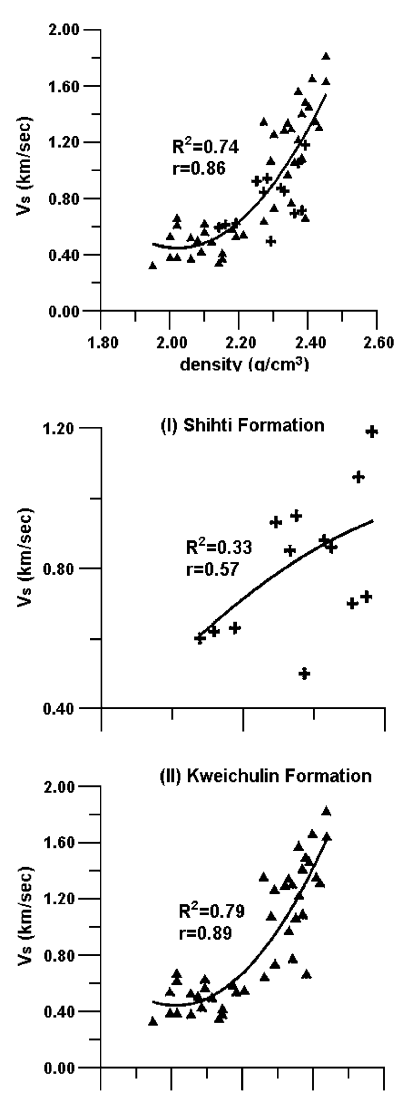

(f) Density
Fig. 6

Regression correction coefficient and the various linear relationships between wave velocity ( $V p$ longitudinal wave, $V s$ shear wave) and physical properties (a, b water content; c, d porosity; e, f density) in the Shihti and Kweichulin Formations 
proportions of quartz and matrix material have no clear relationship with UCS.

\section{Interrelationships with wave velocity}

Figure 5 shows a positive linear relationship between UCS and both the longitudinal and shear wave velocity of the weak sandstone, with quite significant results $(r=0.89,0.85$ and $0.84,0.87$ ) for the Kweichulin and Shihti Formations respectively. The results indicate that when the wave velocity is higher, the UCS is higher, the correlation coefficient for the longitudinal wave velocity/UCS being 0.85 and for the shear wave velocity/UCS $r=0.87$. The regression analysis formulae is $\mathrm{Vs}=0.62 \mathrm{xVp}$.

Figure 6 shows the different relationships between wave velocity and physical properties. It can be seen that there is a weak relationship between wave velocity and water content but a strong correlation with porosity and density (Fig. 6a-f). The correlation coefficients are all quite significant: $r=-0.80,-0.81$ (porosity) and $0.85,0.86$ (density). The relationships between wave velocity and mineral content are scattered and no clear trends can be distinguished.

\section{Interrelationships with slake durability}

Figure 7 shows a positive linear relationship between the first and second cycle slake durability index values and UCS. The first cycle index has a more significant correlation coefficient $(r=0.73)$ in the Kweichulin Formation (Fig. 7a), while the results for the second cycle (Fig. 7b) are less significant $(r=0.68)$, and statistically the other
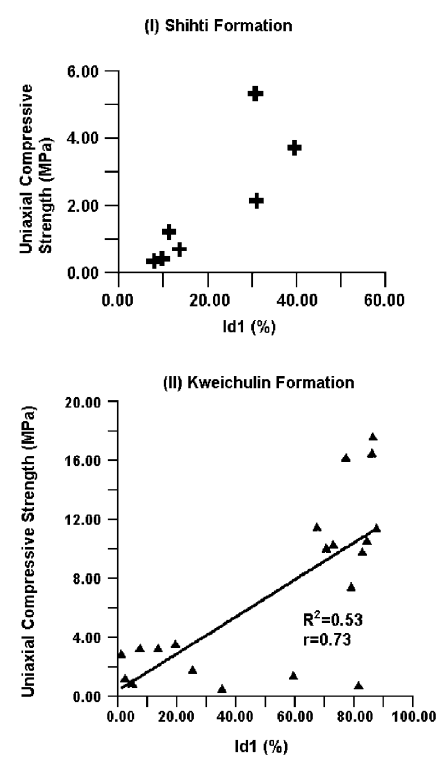

(a) First cycle index
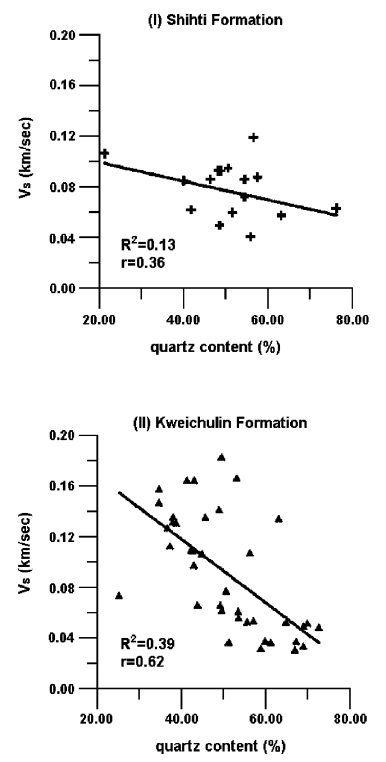

(d) Quartz conten


(b) Second cycle index
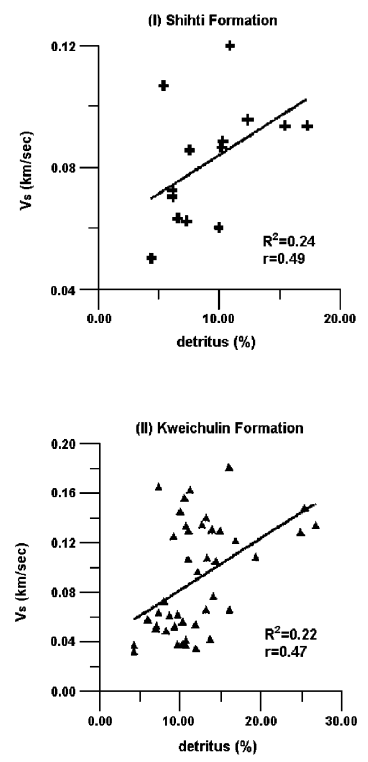

(e) Detrlyus
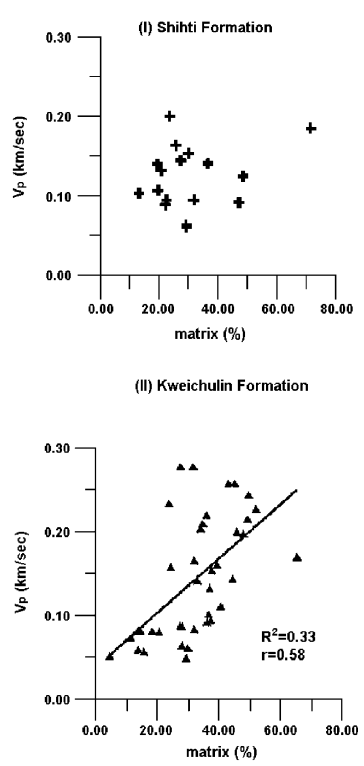

(c) Matrix
Fig. 7

Regression correction coefficient and the various linear relationships between uniaxial compressive strength and slaking durability [a first cycle index (Id1); b second cycle index (Id2); c matrix; d quartz content; e detritus] in the Shihti and Kweichulin Formations 
results indicate that there is no clear relationship between slake durability and either UCS or mineral content.

\section{Conclusions}

Although the main constituent of the matrix of the rocks in the study area is clay minerals, the types found in the Kweichulin and Shihti Formations are quite different. The Shihti Formation contains only rare amounts of smectite and chlorite but is rich in kaolinite, whereas the Kweichulin Formation contains more illite and chlorite.

When the weak sandstone is denser, the UCS is higher. When the porosity is less than $15 \%$ or the density is more than $2.3 \mathrm{~g} / \mathrm{cm}^{3}$, the decreasing porosity affects the UCS. The results indicate a positive relationship between UCS and the proportion of matrix/detritus material. Although UCS increases slightly with increasing quartz content, the relationship is unclear and it is concluded that mineral composition cannot be considered a major factor affecting either the UCS or the wave velocity of the weak sandstone studied.

The regression analyses showed a positive linear correlation between wave velocity and UCS. Slake durability is not significantly related to either UCS or mineral content.

Acknowledgements The authors extend their thanks to Prof. L.A. Lee, Institute of Statistic Analysis, Academy Sinica, and Prof. T.H. Huang, Department of Civil Engineering, National Taiwan University, Prof. C.L. Pan, Ministry of Economic Affairs, Dr. H.C. Lee, Department of Civil Engineering, Chungyun University, Dr. C.C. Chen, Sinotech Engineering Consultants, and Dr. Del Dobyns, Ming Chuan College, for their constructive comments. This study was supported by the National Science Council, China (NSC 862116-M-002-016).

\section{References}

ASTM (1980) Annual book of ASTM standards-natural building stones. Soil and rock, part 19. American Society for Testing Materials, Philadelphia, $634 \mathrm{pp}$

Atkinson BK (1982) Subcritical crack propagation in rocks: theory, experimental results and applications. J Struct Geol $14: 41-56$

Barton ME, Mockett LD, Palmer SN (1993) An engineering geological classification of the soil/rock borderline materials between sands and sandstones. In: Cripps JC, Coulthard JM, Culshaw MG, Forster A (eds) The engineering geology of weak rock. Eng Group Geol Soc Spec Publ 8:125-138

Bell FG (1978) The physical and mechanical properties of the Fell Sandstones, Northumberland, England. Eng Geol 12:1-29

Bell FG, Culshaw MG (1993) A survey of the geotechnical properties of some relatively weak Triassic sandstones. In: Cripps JC, Coulthard JM, Culshaw MG, Forster A (eds) The engineering geology of weak rock. Eng Group Geol Soc Spec Publ 8:139-148

Bieniawski ZT (1984) Rock mechanics design in mining and tunneling. AA Balkema, Rotterdam

Brown ET (ed) (1981) Rock characterization, testing, and monitoring: ISRM suggested methods. Pergamon, Oxford, $211 \mathrm{pp}$

Gamble JC (1971) Durability-plasticity classification of shales and other argillaceous rocks. PhD Thesis, University of Illinois, Urbana

Geological Society London (1970) The logging of rock cores for engineering purposes. Q J Eng Geol 3(1):1-24

Gunsallus KL, Kulhaway FH (1984) A comparative evaluation of rock strength measures. Int J Rock Mech Min Sci Geomech Abst 21:233-248

Hawkins AB, McConnell BJ (1992) Sensitivity of sandstone strength and deformability to changes in moisture content. Q J Eng Geol 25:115-130

Ho CS (1986) An introduction to the geology of Taiwan: explanatory text of the geologic map of Taiwan. Ministry of Economic Affairs, Taipei, $164 \mathrm{pp}$

Huang CS (1988) No. 4 of Taiwan geological map. Central Geological Survey, Taipei, $46 \mathrm{pp}$

ISRM (1978) Suggested methods for the quantitative descriptions of discontinuities in rock masses. Int J Rock Mech Min Sci 15(6):319-368

Olivera R (1993) The engineering geology of weak rock. In: Cripps JC, Coulthard JM, Culshaw MG, Forster A (eds) Weak rock materials. Eng Group Geol Soc Spec Publ 8:5-15

Onodera TF, Asoka KHM (1980) Relation between texture and mechanical properties of crystalline rocks. Bull Int Assoc Eng Geol 22:173-177

Shakoor A, Bonelli RE (1991) Relationship between petrographic characteristics, engineering index properties and mechanics properties of selected sandstone. Bull Int Assoc Eng Geol 28:55-71

Ulusay R, Tureli K, Ider MH (1994) Prediction of engineering properties of a selected litharenite sandstone from its petrographic characteristics using correlation and multivariate statistical techniques. Eng Geol 37:135-157

Vutukuri VS, Lama RD, Saluja SS (1974) Handbook on mechanical properties of rocks. Trans Tech Publications, Clausthal, Germany, $280 \mathrm{pp}$

Yuan N (1996) The characteristics study of weak sandstone texture in east part of Taipei basin. MSc Thesis, National Taiwan University, Taipei, $130 \mathrm{pp}$ 